\title{
Heat Conduction Through Insulating Supports in Very Low Temperature Equipment ${ }^{1}$
}

\author{
R. P. Mikesell and R. B. Scott
}

\begin{abstract}
An apparatus is described that is used to measure the heat conduction through insulating supports of storage vessels for cryogenic liquids and presents the data obtained from the conduction measurements. Two types of supports were tested: (1) multiple-contact supports in the form of stacks of thin metallic plates or spirally wound strips, and (2) nonmetallic spheres. The high thermal resistance of the multiple-contact supports arises from the numerous relatively poor contacts between the individual plates. Some special treatments of the plates were tried, and two of these, perforating and dusting, were found to be effective. Pyrex-glass spheres were also found to be excellent insulators, but, of course, are not as rugged as a stack of metal plates. Of the untreated plates tested, those of stainless steel $(0.0008$ inch thick) were found to be the best insulators per unit length of stack. The heat conduction through these plates, at a load pressure of 1,000 pounds per square inch, was found to be 2 percent of the conduction by a solid sample of the same metal having the same dimensions.
\end{abstract}

\section{Introduction}

The most efficient containers for storing and transporting low-temperature liquids, such as liquid oxygen, nitrogen, and hydrogen, are the vacuumjacketed type known as Dewar vessels. In the past, several types of heat insulators have been used to bridge the vacuum space and furnish support for the inner container. For small laboratory-type Dewars, the design of insulators is not a major problem, but when designing a vacuum-insulated container of several hundred liters or more, which must have ruggedness to withstand the shocks and vibration of transportation by any type of carrier, the problem of insulating supports becomes a serious one.

The recent development of a large aluminum Dewar at the Bureau's Cyrogenic Engineering laboratory included the design of some new type insulating supports, which were of such a nature that their insulating properties could not be computed from the thermal conductivity of the materials from which they were constructed. For this reason, an apparatus was constructed to measure the heat conduction through these supports. Some of the supports were found to have such good insulating and structural properties that it is believed they will have an extended usefulness, and that information obtained from the tests will have general value in the design of Dewar equipment.

\section{Experimental Details}

\subsection{Description of Apparatus}

In order to simulate conditions actually encountered in practice, the calorimeter for measuring the heat conduction was itself a Dewar vessel. With this apparatus it was possible to measure the total heat conduction of the specimen when it was subjected to loads ranging from approximately 30 pounds to approximately 1,050 pounds and under the following temperature conditions: (1) room temper-

\footnotetext{
This work was sponsored by the U. S. Atomic Energy Commission.
}

ature to liquid-nitrogen temperature $\left(296^{\circ}\right.$ to $\left.76^{\circ} \mathrm{K}\right)$, (2) liquid-nitrogen to liquid-hydrogen temperature $\left(76^{\circ}\right.$ to $\left.20^{\circ} \mathrm{K}\right)$, and (3) room temperature to liquidhydrogen temperature $\left(296^{\circ}\right.$ to $\left.20^{\circ} \mathrm{K}\right)$. These temperatures are the boundary conditions encountered in liquid-hydrogen Dewars, which are provided with a liquid-nitrogen-cooled radiation shield between the liquid hydrogen and the room-temperature shell.

The apparatus (fig. 1) was designed so that the calorimeter is a metal Dewar with the test specimen acting as a separating and insulating member. The specimen is placed between the bottom plate of the inner container, into which is poured liquid nitrogen or hydrogen, and the bottom plate of the outer container, which is at room temperature or liquidnitrogen temperature. A 5-liter Dewar containing liquid nitrogen surrounds the calorimeter when it is required to have the exterior wall of the calorimeter at liquid-nitrogen temperature.

The outside container is secured in a vertical position by means of the $\bigcirc$-ring flange, which rests upon a wall bracket not shown in the diagram. The -ring seal is completed by a top flange, through the center of which passes a tube (8-18 stainless steel, $1 \frac{1}{1 / 4}$-in. outside diameter, $1 / 16$-in. wall), which is connected to the inner container. The vacuum system, consisting of a cold trap, diffusion pump, and forepump, is connected to the outer container.

The central tube serves both as the neck of the calorimeter-Dewar and as the compression member for transmitting the load from the fulcrum point of the lever arm to the specimen. This vertical load is the force resulting from a movable weight mounted on a lever arm. A metal bellows permits the central tube to move vertically through guides that also prevent horizontal motion. The brass plate is soldered to the bellows, is sealed to the outer container by means of an 0 -ring and is secured in position by four screws. The unit consisting of the inner container or calorimeter, the central tube, the bellows, and the top flange may be easily withdrawn from the outer container to enable one to change the test specimen. 
In order to reduce heat radiation from the side, the surfaces that face the insulating vacuum are covered with bright aluminum sheet. To intercept radiation from above, horizontal metal disks are placed along the central tube both inside and outside.

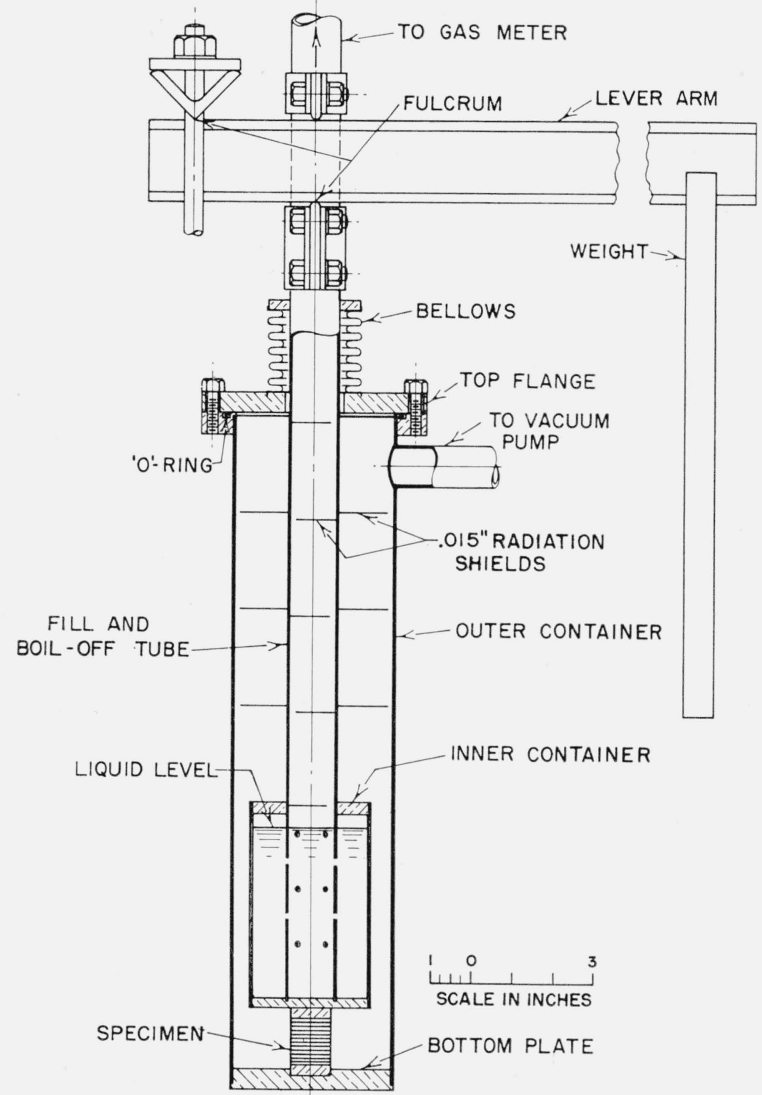

FIGURE 1. Cross section of the calorimetric apparatus.

\subsection{Test Specimens}

The specimens measured in the tests are described $n$ tables 1 and 2 .

The round plates (A, fig. 2) 1 in. in diameter, are mounted between brass end plates of the same diameter. Nylon threads tied through small holes in the plates keep them in place. The rectangular plates are mounted in the same manner, with the diagonal of each rectangle approximately the same length as the diameter of the circular end plates. The spheres (B, fig: 2) are held between two stainless-steel plates, each of which has three matching spherical depressions of somewhat larger diameter than that of the spheres (spheres $3 / 16$-in. radius, depression $1 / 4$-in. radius). This assembly is also tied together with threads to prevent dislodgment of the spheres during test.

TABLE 1. Nonmetallic spheres

\begin{tabular}{|c|c|c|}
\hline Specimen & Dimensions & Comments \\
\hline $\begin{array}{l}\text { Three Pyrex-glass- } \\
\text { spheres. }\end{array}$ & $\begin{array}{l}\text { Each sphere, } 0.375 \text { - } \\
\text { in. diameter. }\end{array}$ & $\begin{array}{l}\text { Made from semipolish No. } \\
774 \text { clear chemical glass, } \\
\text { manufactured by the J. R. } \\
\text { Kilburn Glass Co., Chart- } \\
\text { ley, Mass. }\end{array}$ \\
\hline $\begin{array}{l}\text { Three soda lime } \\
\text { spheres. }\end{array}$ & $\begin{array}{l}\text { A verage diameter of } \\
\text { spheres, } 0.42 \text { in. }\end{array}$ & $\begin{array}{l}\text { Manufactured by Hans L. } \\
\text { Landay, Boulder, Colo. }\end{array}$ \\
\hline $\begin{array}{l}\text { Three ceramic } \\
\text { spheres. }\end{array}$ & $\begin{array}{l}\text { Each sphere, 0.39- } \\
\text { diameter. }\end{array}$ & $\begin{array}{l}\text { Made from Coors type AB-2 } \\
\text { ceramic " high-strength } \\
\text { alumina", manufactured } \\
\text { by the Coors Porcelain Co., } \\
\text { Golden, Colo. }\end{array}$ \\
\hline $\begin{array}{l}\text { Three Micarta } \\
\text { linen-impreg- } \\
\text { nated spheres. }\end{array}$ & $\begin{array}{l}\text { Each sphere, } 0.375- \\
\text { in. diameter. }\end{array}$ & $\begin{array}{l}\text { Manufactured by Westing- } \\
\text { house Elect. Mfg. Corp. }\end{array}$ \\
\hline
\end{tabular}

TABLE 2. Multiple-contact specimens (metallic)

\begin{tabular}{|c|c|c|c|}
\hline Specimen & $\begin{array}{l}\text { Number } \\
\text { of plates }\end{array}$ & Dimensions & Comments \\
\hline $\begin{array}{l}\text { Monel round plates: } \\
\text { Clean plates } \\
\text { Greased plates. }\end{array}$ & $\begin{array}{l}52 \\
52\end{array}$ & 1-in. diameter, 0.017-in. thickness ... & $\left\{\begin{array}{c}\text { Greased with Dow-Corning high-vacuum } \\
\text { grease. }\end{array}\right.$ \\
\hline $\begin{array}{l}\text { Type } 304 \text { stainless-steel round plates: } \\
\text { Clean plates }\end{array}$ & 49 & 1-in. diameter, 0.0195-in. thickness ...... & \\
\hline $\begin{array}{l}\text { Type } 302 \text { stainless-steel round plates: } \\
\text { Clean plates } \\
\text { Clean plates } \\
\text { Clean plates } \\
\text { Clean plates } \\
\text { Dusted plates. }\end{array}$ & $\begin{array}{l}315 \\
313 \\
209 \\
148 \\
345\end{array}$ & 1-in. diameter, 0.0008-in. thickness & $\begin{array}{l}\text { Dusted with a thin layer of manganese } \\
\text { dioxide. }\end{array}$ \\
\hline $\begin{array}{l}\text { Type } 304 \text { stainless-steel rectangular plates: } \\
\text { Clean, plain plates. } \\
\text { Clean, perforated plates. }\end{array}$ & $\begin{array}{r}92 \\
107\end{array}$ & $\begin{array}{l}9 / 16 \text { by } 3 / 4 \text { in., } 0.004 \text {-in. thickness } \\
9 / 16 \text { by } 3 / 4 \text { in., } 0.004 \text {-in. thickness. } 18 \text { 7/64-in.- } \\
\text { diameter holes comprise approximately } 40 \% \\
\text { of total area of a plate. }\end{array}$ & \\
\hline $\begin{array}{l}\text { Alternate layered stack of plain and perforated } \\
\text { plates. }\end{array}$ & 61 of each & $\begin{array}{l}9 / 16 \text { by } 3 / 4 \text { in., } 0.004 \text {-in. thickness. } 18 \text { 7/64-in.- } \\
\text { diameter holes comprise approximately } 40 \% \\
\text { of total area of a plate. }\end{array}$ & $\begin{array}{l}\text { The holes of each plate were staggered with } \\
\text { respect to the holes of the adjacent plate. }\end{array}$ \\
\hline Dusted plain plates ................. & 110 & $9 / 16$ by $3 / 4$ in., 0.004-in. thickness & $\begin{array}{l}\text { Holes of adjacent perforated plates were } \\
\text { staggered. }\end{array}$ \\
\hline Teflon layered stack of plain plates... & 110 & $9 / 16$ by $3 / 4$ in., 0.004 -in. thickness ...... & $\begin{array}{l}\text { The metal plates were separated from each } \\
\text { other by Teflon film } 0.00025 \text {-in. thick. }\end{array}$ \\
\hline
\end{tabular}




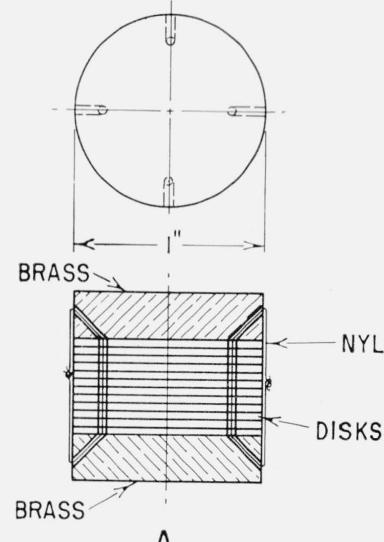

A

FIGURE 2. Method for mounting the specimens

\subsection{Experimental Procedure}

With the specimen in place, the calorimeter supplied with liquid hydrogen or nitrogen, the required load applied, and an adequate vacuum (less than $10^{-5} \mathrm{~mm} \mathrm{Hg}$ ) in the insulating space, the volume of gas evaporated from the calorimetric liquid is determined with a wet test gas meter. Readings are continued until a constant rate of evaporation gives assurance that equilibrium has been reached. Volume determinations are adjusted to standard conditions and corrected for the partial pressure of water vapor in the meter. Several sets of readings are made with applied load on the specimen.

The rate of heat flow through the specimen cannot be calculated directly from the evaporation rate because (1) part of the evaporation of the liquid during the measurements is caused by heat transfer other than through the specimen, and (2) the relation between evaporation rate and heat conducted through the specimen is not quite linear because some of the heat flowing down the central tube is intercepted by the cold gas flowing up the tube; thus less heat is conducted down the tube when the rate of evaporation of the liquid is increased. Instead of trying to determine the magnitude of these incidental heat leaks, their effects were taken into account simply by calibrating the apparatus with a known heat input. This was done by lifting the inner container until it no longer made contact with the specimen and conducting another series of measurements of the gas evolved when known values of electric power were supplied to a heater immersed in the liquid in the inner container. The amount of heat conducted through the specimen during a test measurement is assumed to be the same as that supplied to the heater to produce a given rate of evaporation. This assumption is justified if the conditions during the measurements of heat conduction with applied loads are maintained during the calibration measurements.

\section{Data and Discussion}

\subsection{Accuracy of the Data}

The values of heat conduction obtained with this apparatus are accurate in most cases to approximately 10 percent. The main causes of error were the following: (1) The fluctuations in the magnitude of the incidental heat leaks, though small, did become important in the measurement of the conduction through the very good insulators, and (2) there were small changes in heat conduction resulting from variations in the exact manner of mounting or loading the specimen.

\subsection{Untreated Stacked Plates}

Six multiple contact specimens were tested between nitrogen $\left(76^{\circ} \mathrm{K}\right)$ and room temperature; five of these were stacks of stainless-steel plates, and the sixth was a stack of Monel plates. Two specimens were tested between liquid-hydrogen temperature $\left(20^{\circ} \mathrm{K}\right)$ and liquid-nitrogen temperature $\left(76^{\circ} \mathrm{K}\right)$. Since the support of a Dewar is, in most cases, loaded warm, i. e., the load is applied when the support is at room temperature, the data for each specimen, with the exception of the Monel stack, is presented for warm loadings. The Monel stack was loaded cold, i. e. the load was applied when one end of the specimen was at nitrogen temperature. It was found that the conduction by a stack of plates (0.004 in.) subjected to a high pressure was approximately 30 percent greater when the stack was loaded warm than when it was loaded cold.

The results on clean multiple-contact, metal supports ${ }^{2}$ are shown in figures $3 \mathrm{a}, 3 \mathrm{~b}$, and $3 \mathrm{c}$, wherein the heat current per unit area is plotted as a function of the pressure on the specimen. The heat conduction through the plates increased with the pressure for two reasons: (1) the area of contact surface was increased, and (2) the heat paths became shorter through a given stack of plates. The conduction was found to be proportional to something less than the first power of the pressure, there being a tendency for the curves to level off as increased pressure had less effect. Thus, the stack of plates acted as a good insulator, even at the higher pressures.

The points below a pressure of 300 psi were not especially reliable because the exact values of the lower pressures, as well as the measured conduction rates, are somewhat in doubt.

Figure 4, on which these same curves are plotted on log-log paper, shows the conduction to be proportional to approximately the 0.67 power of the pressure for the nitrogen- to room-temperature range, and proportional to approximately the 0.86 power for the hydrogen- to nitrogen-temperature range. As the heat conduction by a stack of plates was found to be proportional to less than the first power of the load, it is concluded that such a support should be designed for high loading per unit area,

2 Such an arrangement for use as an'insulating support is the subject of a patent application for the AEC by B. LW.1Birmingham, E. H. Brown, R. B. Scott, and P.C. Vander Arend. 


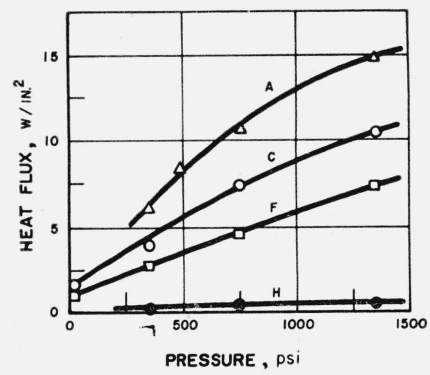

Figure 3a. Heat conducted as a function of mechanical pressure of stacks of type 302 round stainless-steel plates, each plate 0.0008 in. thick.

A $(\triangle), 148$ plates; $\mathrm{C}(\bigcirc), 209$ plates; $\mathrm{F}(\square), 313$ plates; $\mathrm{H}(\bullet), 315$ plates. Boundary temperatures for $\mathrm{A}, \mathrm{C}$, and $\mathrm{F}$ are $76^{\circ}$ and $296^{\circ} \mathrm{K}$; for $\mathrm{H}, 20^{\circ}$ and $76^{\circ} \mathrm{K}$.

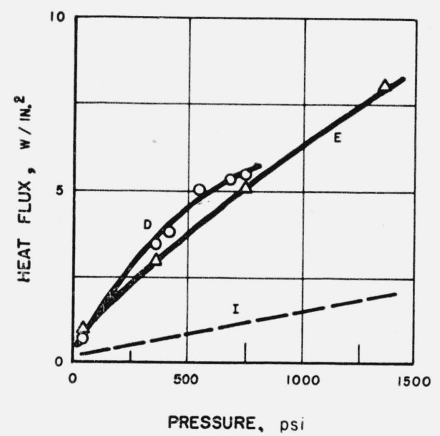

Figure 3b. Heat conducted through stacks of thick plates where the boundary temperatures are $76^{\circ}$ and $296^{\circ} \mathrm{K}$.

$\mathrm{D}(\bigcirc)$, a stack of 52 round Monel plates, 0.017 in. thick; $\mathrm{E}(\triangle)$, a stack of 49 type 304 round, stainless-steel plates, 0.0195 in. thick. Curve I shows the conduction that would occur through a stack of 0.0008 in. plates the same height as the stack of 0.0195 -in. plates. The conduction is extrapolated from the conduction by a stack of 313 plates, 0.0008 in. thick.

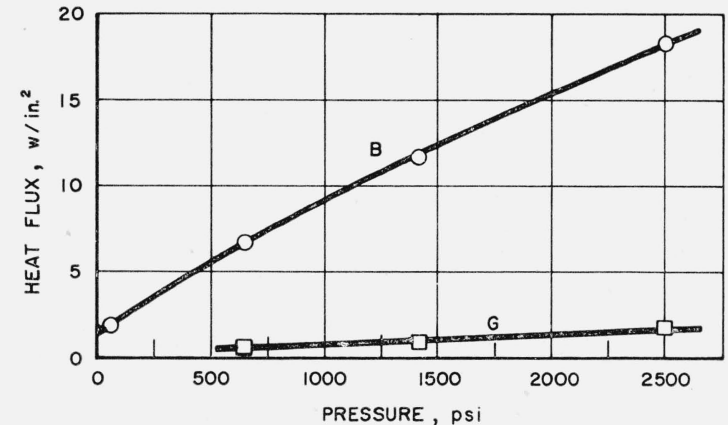

FIGURE 3c. Heat conducted through a stack of 92 type 304 rectangular, stainless-steel plates, 0.004 in. thick.

The boundary temperatures for $\mathrm{B}(\bigcirc)$ are $76^{\circ}$ and $296^{\circ} \mathrm{K}$; for $\mathrm{G}(\square), 20^{\circ}$ and $76^{\circ} \mathrm{K}$.

i. e., the cross-sectional area should be made as small as is consistent with strength and other design considerations.

The concept of thermal resistance is introduced here as an aid in comparing and correlating data on different specimens. Thermal resistance is defined as the temperature difference divided by the

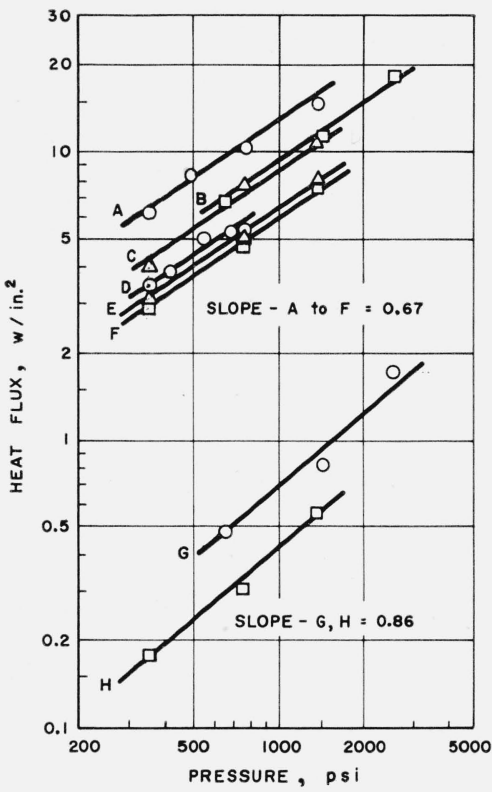

Figure 4. A log-log presentation of the data given in figures $3 a, 3 b$, and $3 c$, demonstrating that the heat current is approximately proportional to the 0.67 power of the pressure in the upper temperature range $\left(76^{\circ}\right.$ to $\left.296^{\circ} \mathrm{K}\right)$, and to the 0.86 power of the pressure in the lower temperature range $\left(20^{\circ}\right.$ to $\left.76^{\circ} \mathrm{K}\right)$.

A (○), 148 plates, 0.0008 in. thick; B ( $\square), 92$ plates, 0.004 in. thick; C ( $\triangle$ ), 209 plates, 0.0008 in. thick; $\mathrm{D}(\bigcirc), 52$ plates, 0.017 in. thick; $\mathrm{E}(\triangle), 49$ plates, 0.0195 in. thick; F ( $\square)$, 313 plates, 0.0008 in. thick; G $(O)$, 92 plates, 0.004 in. thick; $H(\square), 315$ plates, 0.0008 in. thick.

heat current (in analogy to its electrical equivalent). Thermal resistance is temperature dependent, but it is permissible to use an average value for comparing two stacks under the same temperature difference. As there were a large number of stacked plates in these tests, it was reasonable to expect that the resistance would be proportional to the number of plates, i. e., that the end effects would be negligible.

Three specimens of the 0.0008-in.-round stainlesssteel plates were tested, each with a different number of plates. In figure 5 it is shown that the thermal resistance of a stack of plates varies linearly with the number of plates in the stack. Thermal resistance of unit area per plate as a function of the thickness of each plate is shown in figure 6 . For many design applications a certain volume may be available for the insulating member. Hence, consistent with strength and cost considerations, it is desirable to know what thickness the plates should have to provide adequate heat insulation. Thermal resistance of unit area per unit length of stack as a function of plate thickness is plotted in figure 7 . The length of the stack was determined by multiplying the number of plates by the thickness of each plate; this calculated length was in close agreement with the length measured when the stack was subjected to a pressure of $1,000 \mathrm{psi}$. Points for the curves of figures 6 and 7 are taken from the curves of figures $3 \mathrm{a}, 3 \mathrm{~b}$, and $3 \mathrm{c}$ for the 


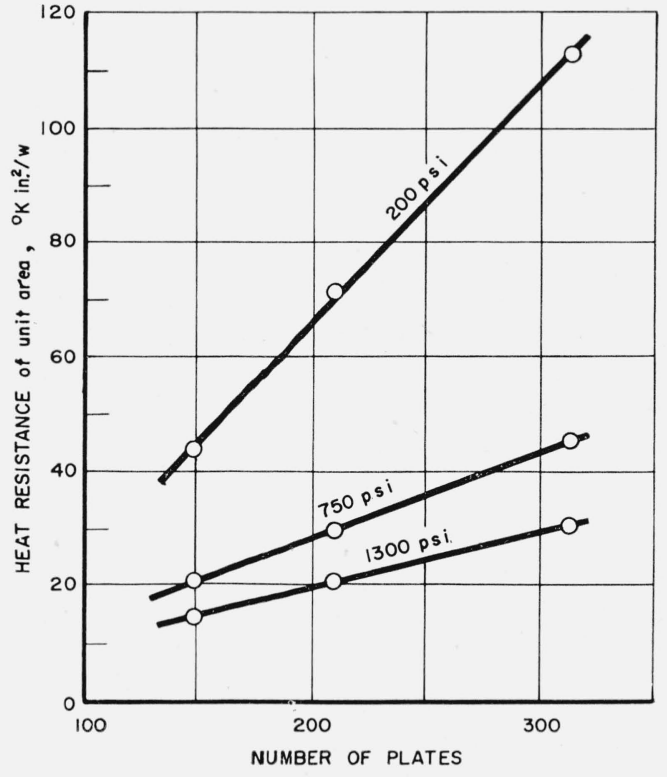

Figure 5. Observed linear increase of the thermal resistance with the number of plates contained in a stack.

The plate thickness is 0.0008 in.; the boundary temperatures are $76^{\circ}$ and $296^{\circ} \mathrm{K}$.

0.0008-in. stainless-steel round plates, the 0.0195in. stainless-steel rectangular plates, and the 0.004in. stainless-steel round plates. It is seen that the 0.0195-in. stainless-steel round plates had a higher thermal resistance per plate than the others, the explanation being that the thin plates were pressed into better contact with each other with a given applied pressure. However, for a given length of stack, the thin plates produced a greater total thermal resistance. This is shown by the dotted curve, I, figure 3b. No implication is intended that the slopes of approximately $\frac{1}{2}$ and $-1 / 2$ of the lines of figures 6 and 7 have any significance other than that of representing the observations. It is probable that for different loads or plate thicknesses these would have other values.

The heat conduction through a stack of plates was considerably less than the conduction by a solid member of the same metal having the same dimensions, showing that the difference in conduction was due mainly to the total contact resistance of the specimen.

The conduction through a stack of 0.0008-in.-thick stainless-steel plates under a pressure of 1,000 psi was found to be approximately 2 percent of the conduction by a solid member; for the 0.0195-in. stainless steel round plates at 1,000 psi, 8.5 percent; for the 0.004-in.-thick stainless-steel rectangular plates at 1,000 psi, 4.5 percent; and for the 0.017 -in.thick Monel round plates at $600 \mathrm{psi}, 6.5$ percent.

The 0.0008 -in. and the 0.004 -in. plates were tested between liquid-nitrogen and liquid-hydrogen temperatures. Table 3 shows the comparison between these specimens. In the case of both the 0.0008 -in. and the 0.004-in. plates, the specimen was loaded warm at the higher pressures; the load was reduced to the lower pressures after the specimen was cold. The

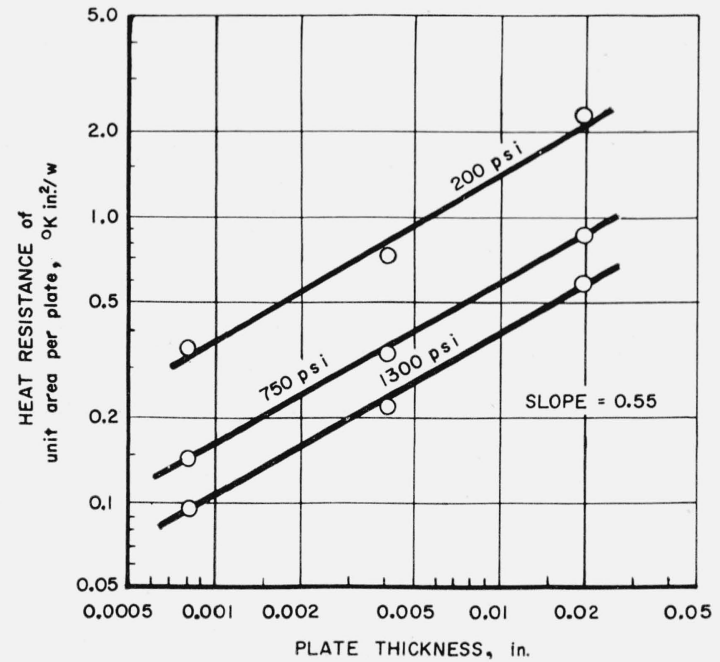

Figure 6. A log-log presentation demonstrating that the heat resistance per plate increases approximately as the square root of the individual plate thickness.

The boundary temperatures are $76^{\circ}$ and $296^{\circ} \mathrm{K}$.

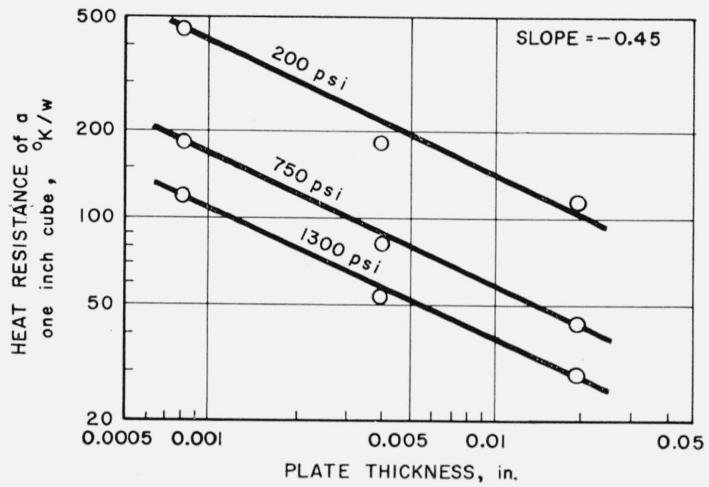

Figure 7. A log-log presentation demonstrating that the heat resistance per unit length of a stack varies approximately as the inverse square root of the individual plate thickness.

The boundary temperatures are $76^{\circ}$ and $296^{\circ} \mathrm{K}$.

ratio of the heat conducted between $296^{\circ}$ and $76^{\circ} \mathrm{K}$ to that conducted beween $76^{\circ}$ and $20^{\circ} \mathrm{K}$ is of interest. The conduction ratio of a solid member of the same type of metal and the same dimension between the two temperature intervals would be 9 to 1 . The greater ratio in the case of the stacked plates is an indication that the thermal resistance of the contacts increases as the temperature is decreased.

TABle 3. Comparison of 0.0008-in. and 0.004-ir. plates

\begin{tabular}{|c|c|c|}
\hline Pressure & $\begin{array}{l}\text { Specimen } \\
\text { plates }\end{array}$ & $\begin{array}{c}\text { Conduction ratio } \\
\text { (Conduction at } 76^{\circ} \\
\text { to } 296^{\circ} \mathrm{K} \div \text { con- } \\
\text { duction at } 20^{\circ} \\
\text { to } 76^{\circ} \mathrm{K} \text { ) }\end{array}$ \\
\hline $\begin{array}{c}p s i \\
754 \\
1,346 \\
1,407 \\
2,509\end{array}$ & $\begin{array}{l}\text { in. } \\
0.0008 \\
.0008 \\
.004 \\
.004\end{array}$ & $\begin{array}{l}15.5 \text { to } 1 \\
13.3 \text { to } 1 \\
14.2 \text { to } 1 \\
10.6 \text { to } 1\end{array}$ \\
\hline
\end{tabular}




\subsection{Specially Treated Stacked Plates}

\section{a. Dusted Plates}

Because the objective of the work was to devise sturdy supports with the best possible insulating properties, methods of decreasing the heat conduction were studied. S. C. Collins of Massachusetts Institute of Technology predicted that a very slight coat of dust would greatly increase the thermal resistance. He had observed that a few dust particles detectable only under a microscope were sufficient to spoil the effectiveness of a thermal switch. Manganese dioxide was chosen to be the insulating dust for several reasons. It is only a fair conductor of heat and has moderate hardness. It can be ground into a fine powder that will cling to the surface of the plates, so that little of the dust is lost in the assembling of the supports. The dust coat on each plate was of such a small magnitude that the total length of the multiplate specimen was not significantly changed. The results for the dusted plates, as illustrated in figure 8 , curves $\mathrm{A}$ and $\mathrm{E}$, show that the heat resistance of unit area per plate of the stack of dusted plates is much higher than that of the stack of clean rectangular plates.

\section{b. Perforated Plates}

Another good insulating device was found to be a stack of perforated rectangular plates. The results on these plates are shown in figure 8, curve B. Figure 9 shows the plan of a perforated plate. The net area is 60 percent of the area of a plain rectangular plate. The thermal resistance of these plates was found to be higher than that of the plain rectangular plates because of the smaller area of the perforated plates and because the plates were stacked in such a manner that the holes of the adjacent plates did not aline, resulting in longer heat paths through the stack. Because the production of the perforated plates that might be used for an insulating support in a specific case was found to be expensive, it was also decided to try stacking the perforated and plain rectangular plates in alternate layers. In comparing the thermal resistance of the stacks of the three types of rectangular plates, each tested at a total load of $422 \mathrm{lb}$, it was found that the stack of plain plates had a resistance of $0.260^{\circ} \mathrm{K}$-in. ${ }^{2}$-watt ${ }^{-1}$ per plate; the stack of perforated plates, 0.420 , and the alternate layered stack, 0.370 .

\section{c. Teflon-Separated Plates}

A stack of rectangular plates with thin (approximately 0.00025 in.) films of Teflon placed between them was found to be a comparatively poor insulator at the low pressures. The high compressibility of the plastic resulted in a greater area of contact between it and the metal layers than would be realized between metal layers alone. However, at the higher pressures, the Teflon-layered stack was a good insulator, the area of the thermal contact having approached a constant value. At all pressures the plastic acted as a good insulator because of its low thermal conductivity. The conduction curve for the Teflon-layered plates is shown in figure 10, curve D.

\section{d. Greased Plates}

The application of grease to the Monel plates of a stack resulted in a decrease of heat resistance of nearly 16 percent at a pressure of 600 psi, as shown in figure 10, curve B (the stack of greased plates was loaded cold). A very thin layer of Dow-Corning high-vacuum grease was applied to each plate. The considerable increase in conduction by the greased plates may be explained in this manner: The coating of grease filled in the small spaces between the plates,

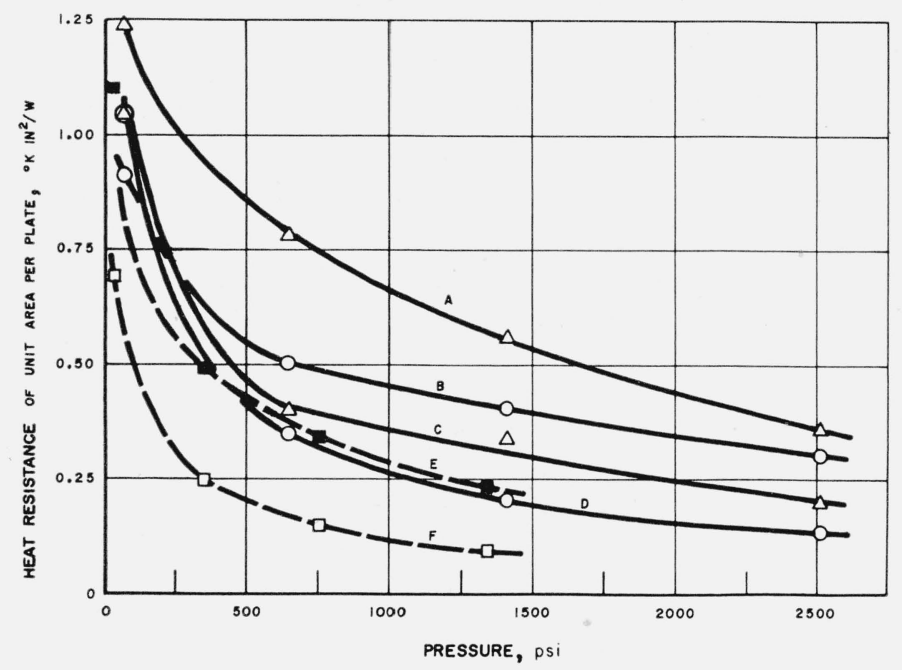

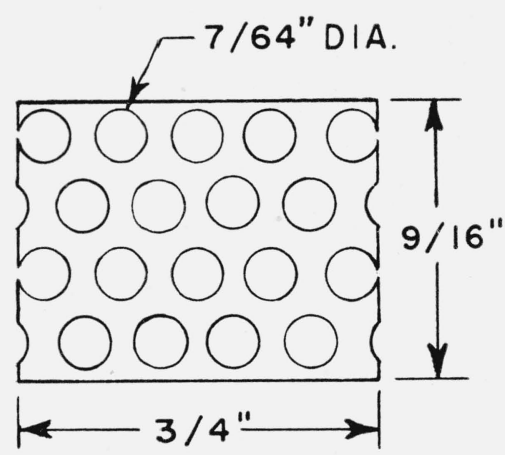

Figure 9 . A perforated plate.

Figure 8. Comparison of the heat resistance of clean plates with that of specially treated plates.

The boundary temperatures are $76^{\circ}$ and $296^{\circ} \mathrm{K}$. A $(\triangle)$, a stack of 0.004 -in. manganese-dioxide-dusted plates; B $(\bigcirc)$, 0.004 -in. perforated plates; C $(\triangle)$, alternate layered stack of 0.004 -in. plain and perforated plates; $\mathrm{E}(\mathbf{D}), 0.0008$-in. dusted plates; $\mathrm{D}(\mathrm{O}), 0.004$-in. clean plates; F ( $\square$ ), 0.0008 -in. clean plates. 


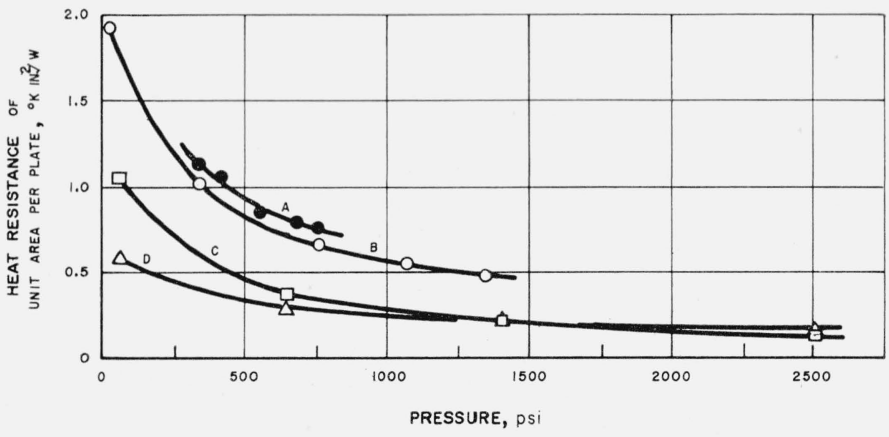

Figure 10. Comparison of the heat resistance of clean plates with that of specially treated plates.

The boundary temperatures are $76^{\circ}$ and $296^{\circ} \mathrm{K}$. A Monel plates; B (○), 0.017-in. grease

, a stack of 0.017 -in. clean $(\triangle), 0.004$-in. Teflon-separated plates.

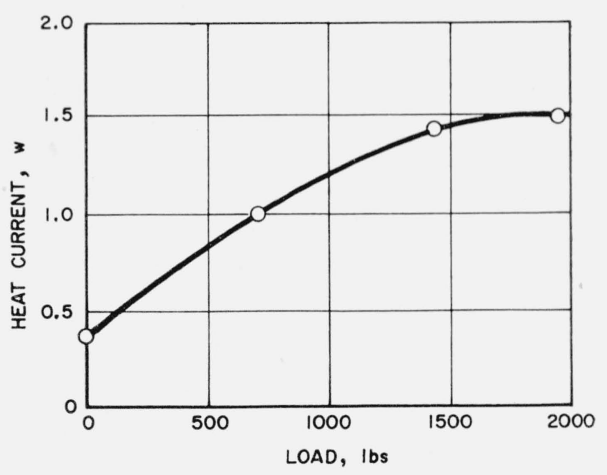

FIGURe 11. Heat conducted as a function of total load on a type 304 stainless-steel strip, 0.0021 in. thick, 1 in. wide, which is dusted with manganese dioxide and rolled into a tight coil.

The boundary temperatures are $76^{\circ}$ and $296^{\circ} \mathrm{K}$. resulting in a more positive thermal contact. It is seen, therefore, that caution should be taken when one assembles a stack of plates, keeping each plate as clean as possible.

\subsection{Application of Multiple-Contact Supports}

A liquid-hydrogen Dewar, designed at the NBSAEC Cryogenic Engineering Laboratory, was constructed with multiple-contact supporting members. Each of these separating members was made by tightly rolling a strip of type 304 stainless steel into a coil, the strip being 0.0021 in. thick, approximately $400 \mathrm{ft}$ long and $1 \mathrm{in}$. wide. The inner diameter of the coil was approximately 2 in. and the outer diameter approximately $5 \mathrm{in.}$ The coil was tested for conduction in an apparatus similar in operation to the original multiple-support testing equipment. The results of the conduction tests between nitrogen and room temperature, using a strip dusted with manganese dioxide, are shown in figure 11. It was not feasible to compute the heat conduction by a coil from the conduction by a stack of plates because it was not known how much heat flowed along the circumference of the coil nor how large was the effective cross-sectional area through which the heat flowed.

\subsection{Nonmetallic Spheres}

The resuits of tests on nonmetailic spheres are shown in figures $12 \mathrm{a}, 12 \mathrm{~b}, 12 \mathrm{c}$, and $12 \mathrm{~d}$, wherein the heat current per sphere is plotted as a function of the load per sphere. Each of the spheres in its socket made little more than point contact at no load. The conduction increased with increasing loads because the area of contact was increased, but it tended to level off at the higher loads as this area approached a constant value. The dependence of conduction on pressure also varied with the type of material of the sphere, e. g., if the material was soft, the sphere would flow slightly at the higher loads, resulting in a greater area of contact.
It is seen that of the four types of spheres tested, ceramic was found to be the best conductor and Pyrex glass was found to be the poorest conductor of heat. A load has more effect on the flow of heat through the ceramic spheres because the contact resistance has proportionally more effect in the case of the better conductor. Although the conductivity of Micarta is less than that of Pyrex, the conduction through the Micarta spheres was found to be greater than through the Pyrex spheres, possibly because of the slight flow of Micarta at the higher loads.

There was a small error due to a comparatively small temperature drop across the stainless-steel plates that were used for support of the spheres. The conduction through the spheres was actually greater than was measured.

In all cases, the conduction from $76^{\circ}$ to $20^{\circ} \mathrm{K}$ is very much less than that from approximately $296^{\circ}$ to $76^{\circ} \mathrm{K}$. This is a consequence not only of the smaller temperature interval but also of the great decrease of the thermal conductivity of noncrystalline materials below $76^{\circ} \mathrm{K}$.

Because the purpose of these measurements was to provide information about members that would be expected to have usefulness as insulating supports, some tests were conducted on the spheres to determine their crushing strength. The Pyrex-glass spheres failed at approximately 2,000 lb per sphere (two measurements). The ceramic spheres supported $10,000 \mathrm{lb}$ each without failure.

The conduction data on the spheres should be considered in relation to their compressive strength. At first sight it appears that the higher strength of the ceramic spheres offsets their larger thermal conduction. This, of course, assumes that they will be used at high loads. If a support is designed for loads that would take the full advantage of the strength of the ceramic spheres, it would be necessary to provide hard bearings for the spheres to rest against, possibly of the same ceramic material. For average loads, the Pyrex spheres would be the most suitable. 


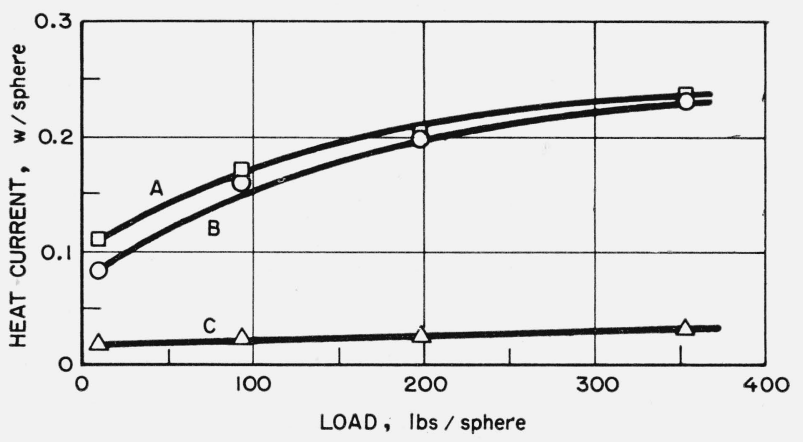

Figure 12a. Heat conducted through Pyrex glass spheres, each sphere 0.375 in. in diameter.

$\underset{T_{2}=76^{\circ} \mathrm{K}}{\mathrm{K}}, T_{1}=20^{\circ} \mathrm{K}, T_{2}=296^{\circ} \mathrm{K} ; \mathrm{B}(\bigcirc), T_{1}=76^{\circ} \mathrm{K}, T_{2}=296^{\circ} \mathrm{K} ; \mathrm{C}(\triangle), T_{1}=20^{\circ} \mathrm{K}$,

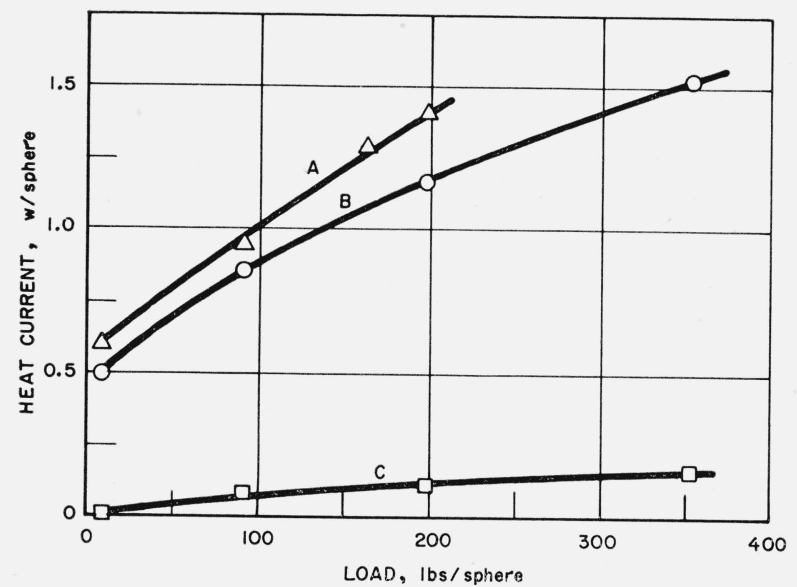

FIGURE 12b. Heat conduction through ceramic spheres, each sphere $0.39 \mathrm{in}$. in diameter.

$\mathrm{A}(\triangle), T_{1}=20^{\circ} \mathrm{K}, T_{2}=296^{\circ} \mathrm{K} ; \mathrm{B}(\bigcirc), T_{1}=76^{\circ} \mathrm{K}, T_{2}=296^{\circ} \mathrm{K} ; \mathrm{C}(\square), T_{1}=20^{\circ} \mathrm{K}$,

\section{Previous Experiments}

The use of multiple contact members as insulating supports was suggested by the experience of other workers who had to go to great pains to obtain good thermal contact in a vacuum.

R. B. Jacobs and C. Starr, in an effort to design a good thermal switch, carried out experiments at MI'T in $1939^{3}$ wherein the heat conducted beiween two optically flat metallic surfaces in close contact with each other in a vacuum was measured as a function of contact pressure. Three different thermal switches were tested, one made of copper, another of silver, and the third of gold.

In 1949, S. C. Collins directed experiments ${ }^{4}$ at MIT similar in nature to the Jacobs and Starr experiment. The thermal resistance between optically flat copper surfaces was measured.

In both these experiments it was found necessary to apply considerable pressure to obtain low thermal resistance.

\footnotetext{
${ }^{3}$ R. B. Jacobs and C. Starr. Thermal conductance of metallic contacts, Rev. Sci. Instr. 10, 140 (April 1939)

${ }^{4}$ As described in a private communication from D. B. Chelton, who wa working with Collins in 1949.
}

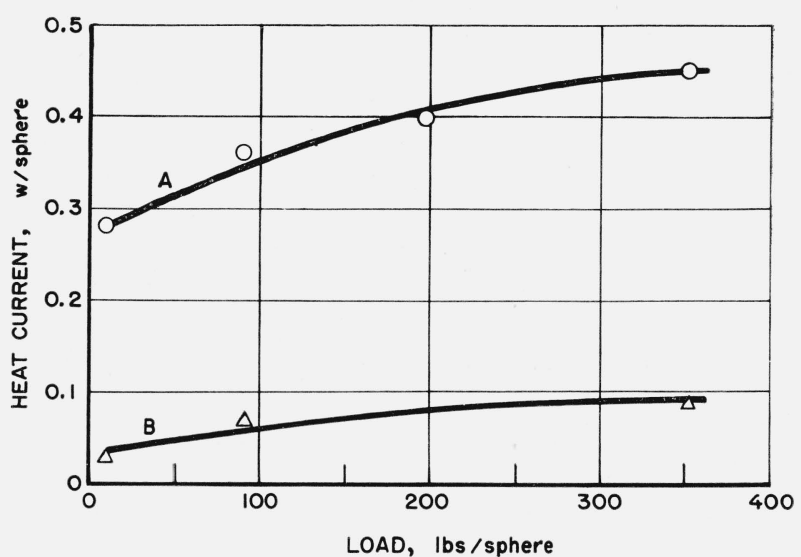

FIGURE 12c. Heat conducted through Micarta spheres, each sphere 0.375 in. in diameter.

A (○), $T_{1}=76^{\circ} \mathrm{K}, T_{2}=296^{\circ} \mathrm{K} ; \mathrm{B}(\triangle), T_{1}=20^{\circ} \mathrm{K}, T_{2}=76^{\circ} \mathrm{K}$.

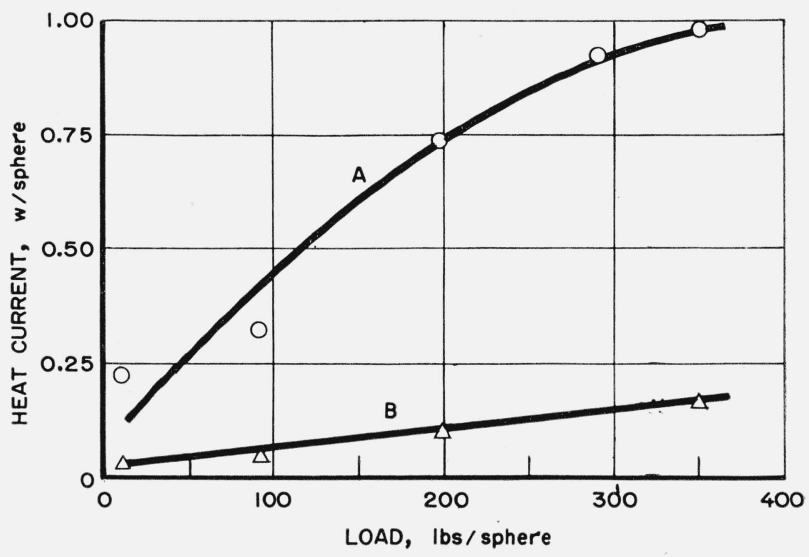

FIGURE 12d. Heat conduction through soda lime spheres, each sphere $0.42 \mathrm{in}$. in diameter.

A (O), $T_{1}=76^{\circ} \mathrm{K}, T_{2}=296^{\circ} \mathrm{K}$; B $(\triangle), T_{1}=20^{\circ} \mathrm{K}, T_{2}=76^{\circ} \mathrm{K}$.

\section{Conclusions}

The most important conclusions to be drawn from these results are (1) the principle of multiple thermal contacts offers the designer of cryogenic equipment a simple rugged support that occupies small space, (2) the best assembly tested consisted of a stack of stainless-steel plates, 0.0008 in. thick. Its thermal conduction when supporting a load of 1,000 psi was only 2 percent of that of a solid conductor of the same dimensions, (3) the insulating value of such a support is enhanced by introducing a tiny amount of dust $\left(\mathrm{MnO}_{2}\right)$ between the plates, and (4) for best results the support should be designed for high loading per unit area.

The authors thank R. L. Powell for his assistance in designing the apparatus and developing the experimental procedure.

Boulder, Colo., August 30, 1956. 